\title{
Effects of Chestnut (Castanea sativa Mill.) Peel Powder on Quality Characteristics of Chicken Emulsion Sausages
}

\author{
Yun-Sang Choi ${ }^{1}$, Ji-Hun Choi', Doo-Jeong Han², Hack-Youn Kim², Mi-Ai Lee², \\ Hyun-Wook Kim², Dong-Heon Song ${ }^{2}$, Ju-Woon Lee ${ }^{3}$, and Cheon-Jei Kim,2* \\ ${ }^{1}$ Research Institute for Meat Science and Culture, Konkuk University, Seoul 143-701, Korea \\ ${ }^{2}$ Department of Food Science and Biotechnology of Animal Resources, Konkuk University, Seoul 143-701, Korea \\ ${ }^{3}$ Radiation Technology Institute, Korea Atomic Energy Research Institute, Jeongeup 580-185, Korea
}

\begin{abstract}
Sausages were prepared with fresh chicken breast meat and pork back fat, and formulated with different amounts of added chestnut (Castanea sativa Mill.) peel and ice water to study the effect on the products. The chicken emulsion sausages formulated with $1 \%, 2 \%$, and $3 \%$ added chestnut peel powder were higher in moisture and ash content, and lower in energy values. The cooking loss, emulsion stability, and viscosity of the sausages were improved by the addition of chestnut peel. The fat content, $\mathrm{pH}$, lightness, hardness, and springiness of the chicken emulsion sausage decreased as the amount of chestnut peel levels increased. The chicken emulsion sausages containing $1 \%$ and $3 \%$ chestnut peel had a higher overall acceptability than the control.
\end{abstract}

Key words: chicken sausage, emulsion sausage, chestnut peel, dietary fiber, sensory evaluation

\section{Introduction}

Chicken meat and products are very popular among consumers, while also providing an excellent source of animal protein for consumers in developing countries (Choi et al., 2010). The production and consumption of chicken meat has increased significantly throughout the world. Many chicken delicatessen meats are currently on the market, chiefly cooked products such as cured thigh meat and fillet, jerky, patties, sausages, and nuggets. These products are becoming more popular due to their sensory characteristics and ease of preparation. Sausage is one of the oldest known forms of processed meat products, and is very popular all over the world. Processed sausage such as emulsion sausage, however, may be high in fat. High fat levels in daily diets are associated with high blood cholesterol levels and undesired weight gain due to excess calories and other serious diet related diseases (Choi et al., 2010; Jiménez-Colmenero et al., 2003). Dietary fat content has been significantly corre-

\footnotetext{
*Corresponding author: Cheon-Jei Kim, Research Institute for Meat Science and Culture, Konkuk University, Seoul 143-701, Korea. Tel: 82-2-450-3684, Fax: 82-2-444-6695, E-mail: kimcj (a)konkuk.ac.kr
}

lated with coronary heart disease, obesity, and cancer (Choi et al., 2009; Nuria et al., 1999).

Among functional foods, dietary fiber plays an important role in the human diet. Dietary fiber in food has been added to various meat products to counteract problems caused by fat reduction, so dietary fiber has been ascribed a steadily increasing role in health and well-being (Choi et al., 2008, 2009; Kim et al., 2010; Lee et al., 2009). Furthermore, dietary fiber incorporated in meat products improves cooking yield, water holding capacity, and textural properties (Choi et al., 2007a; Joo and Chung, 2007). Many researchers have also carried out studies on the addition of dietary fiber to reduced-fat meat products, which helps improve rheological properties and stability (Aleson-Carbonell et al., 2003; Choi et al., 2009, 2010; Fernandez-Gins et al., 2003).

Chestnuts (Castanea sativa Mill.) have become increasingly important in human nutrition because of their nutrient composition and potential beneficial health effects, such as containing considerable amounts of dietary fiber, vitamins, essential fatty acids, and minerals $(\mathrm{K}, \mathrm{Mg}, \mathrm{Fe}$, $\mathrm{Mn}$, and $\mathrm{Cu}$ ) (Inkaya et al., 2009; Yang et al., 2010). It is also a good source of bioactive substances, including lectin, cysteine, proteinase inhibitor, and quercetin (Wang and $\mathrm{Ng}, 2003$ ). It has a long history of use of over 2000 
years in Asian countries such as Korea, China, and Japan, with important and growing economic roles. For many centuries, the chestnut has represented one of the most important food resources of Korean rural areas, but the depopulation of mountain areas has led to a decline in their consumption (Kim et al., 2008). About $60 \%$ of chestnuts grown in Korea are consumed domestically, and the rest are exported to Japan as peeled chestnuts, except for some chestnuts that are processed. Chestnut peels are produced as a by-product of peeled chestnuts and during chestnut processing. It is rich in carbohydrates and is also a good source of tannin compounds, minerals, and dietary fiber. In recent years, chestnut peel has been studied for its potential use in developing functional foods (Jeon and Park, 2000, Jeong et al., 2006; Oh et al., 2004, 2005). However, food with added chestnut peel has a bitter taste and off-flavor due to its containing tannin compounds. The use of chestnut peel in commercial products has so far been limited to the production of animal feed. Also, for meat products, not enough chestnut peel can be applied to it to make it a significant source of dietary fiber. The use of chestnut peel as source of dietary fiber for chicken emulsion sausages was investigated.

The objectives of this study were to evaluate the effects of various chestnut peel levels on the proximate composition, energy value, $\mathrm{pH}$, color, cooking yield, emulsion stability, texture profile analysis, viscosity, and sensory evaluation of chicken meat emulsion type sausages.

\section{Materials and Methods}

\section{Chestnut peel powder preparation and processing}

Commercial samples of dried chestnut (Castanea sativa Mill.) peel were purchased from the local market, ground using a blender (KA-2610, Jworld Tech, Ansan, Korea) for a minute, and passed though a 20-mesh sieve. The chestnut peel powders (moisture content: $6.54 \%$, protein content: $8.11 \%$, fat content: $2.41 \%$, ash content: $0.98 \%$, digestible carbohydrates: $42.21 \%$, and dietary fiber: $33.86 \%$ ) were vacuum-packed and stored at $-20^{\circ} \mathrm{C}$ before they were added into the treatments. The lightness, redness, and yellowness values of chestnut peel powder were 68.09, 5.47, and 11.31, respectively.

\section{Chicken meat emulsion sausages preparation and processing}

Fresh chicken breast meat (M. pectoralis major) and pork back fat (moisture $12.61 \%$, fat $85.64 \%$ ) were purchased from a local processor at $48 \mathrm{~h}$ postmortem. The chicken materials were initially ground through an $8 \mathrm{~mm}$ plate. The pork back fat was also ground through an 8$\mathrm{mm}$ plate. The ground tissue was then placed in polyethylene bags, vacuum packaged using a vacuum packaging system (FJ-500XL, Fujee Tech, Seoul, Korea), and stored at $0^{\circ} \mathrm{C}$ until required for product manufacture. Suitable amounts of the muscle and fat were tempered at $4^{\circ} \mathrm{C}$ for $24 \mathrm{~h}$ prior to emulsion sausage preparation.

Meat packages were thawed (approx. $24 \mathrm{~h}$ at $5 \pm 2^{\circ} \mathrm{C}$, up to between -1 and $-2^{\circ} \mathrm{C}$ ). Each batch of samples consisted of five meat batters which differed in composition with respect to the addition of chestnut peel powder levels $(0$, $1,2,3$, and $4 \%$ ). The five different emulsion sausages were formulated (Table 1) as follows: raw meat was homogenized and ground for $1 \mathrm{~min}$ in a silent cutter (Cutter Nr963009, Scharfen, Germany). 1.6\% NaCl, $0.2 \%$ sodium tripolyphosphate, $1.0 \%$ isolated soy protein, $0.45 \%$ sorbitol, $0.08 \%$ monosodium L-glutamate, $0.07 \%$ onion powder, and $0.07 \%$ ginger powder were added to the meat that had been previously dissolved in water and chilled $\left(2^{\circ} \mathrm{C}\right)$, and then mixed for $1 \mathrm{~min}$. The chestnut peel powder was added to meat batters, which were then homogenized for 6 min. A temperature probe (Kane-May, KM330, Germany) was used to monitor the temperature of the emulsion, which was maintained below $10^{\circ} \mathrm{C}$ during batter preparation. After emulsification, chicken meat batter was stuffed into collagen casings (\#240, NIPPI Inc., Tokyo, Japan; approximate diameter of $25 \mathrm{~mm}$ ) using a stuffer (Stuffer IS-8, Sirman, Italy). The meat batters were

Table 1. Chicken emulsion sausage formulations with various chestnut peel powder levels

(units: \%)

\begin{tabular}{lccccc}
\hline \multirow{2}{*}{ Ingredients } & \multicolumn{5}{c}{ Treatments $^{1)}$} \\
\cline { 2 - 7 } & Control & T1 & T2 & T3 & T4 \\
\hline Chicken breast meat & 50 & 50 & 50 & 50 & 50 \\
Back fat & 25 & 25 & 25 & 25 & 25 \\
Ice & 25 & 24 & 23 & 22 & 21 \\
Chestnut peel powder & - & 1.0 & 2.0 & 3.0 & 4.0 \\
\hline Total & 100 & 100 & 100 & 100 & 100 \\
\hline Salt & 1.6 & 1.6 & 1.6 & 1.6 & 1.6 \\
Sodium tripolyphosphate & 0.2 & 0.2 & 0.2 & 0.2 & 0.2 \\
Isolated soy protein & 1.0 & 1.0 & 1.0 & 1.0 & 1.0 \\
Sorbitol & 0.45 & 0.45 & 0.45 & 0.45 & 0.45 \\
Monosodium L-glutamate & 0.08 & 0.08 & 0.08 & 0.08 & 0.08 \\
Onion powder & 0.07 & 0.07 & 0.07 & 0.07 & 0.07 \\
Ginger powder & 0.07 & 0.07 & 0.07 & 0.07 & 0.07 \\
\hline
\end{tabular}

${ }^{1)}$ Control: chicken emulsion sausage with no addition; T1: chicken emulsion sausage with $1 \%$ chestnut peel powder; T2: chicken emulsion sausage with $2 \%$ chestnut peel powder; T3: chicken emulsion sausage with $3 \%$ chestnut peel powder; T4: chicken emulsion sausage with $4 \%$ chestnut peel powder. 
then heated at $75 \pm 2^{\circ} \mathrm{C}$ for $30 \mathrm{~min}$ in a water bath (Dae Han Co, Model 10-101, Korea). The cooked meat batters were then cooled with cold water. 10-kg batches of each chicken emulsion sausages were prepared in this manner.

\section{Proximate composition}

Moisture (950.46B, oven air-drying method), protein (981.10) $(\mathrm{N} \times 6.25)$, fat $(960.69$, ether extractable component), and ash (920.153, muffle furnace) contents were determined according to the AOAC (2000) procedure. Carbohydrate contents were calculated by the difference among the parameters.

\section{Caloric content}

Total calorie estimates (kcal) for chicken meat emulsion sausages were calculated on the basis of a 100 -g portion using Atwater values for fat $(9 \mathrm{kcal} / \mathrm{g})$, protein $(4.02$ $\mathrm{kcal} / \mathrm{g})$, and carbohydrate $(3.87 \mathrm{kcal} / \mathrm{g})$.

\section{pH}

The $\mathrm{pH}$ values of chicken emulsion meat batter and sausage were measured in a homogenate prepared with 5 $\mathrm{g}$ of sample and distilled water $(20 \mathrm{~mL})$, using a $\mathrm{pH}$ meter (Model 340, Mettler-Toledo GmbH, Schwerzenbach, Switzerland). All determinations were performed in triplicate.

\section{Color evaluations}

The color of chicken emulsion meat batter and emulsion sausage were measured by the CIE LAB system using a color meter (Minolta Chroma meter CR-210, Japan; illuminate $C$, calibrated with white plate, $L^{*}=+97.83, a^{*}=$ $\left.-0.43, b^{*}=+1.98\right)$. Six measurements for each of five replicates were taken. Lightness $\left(\mathrm{L}^{*}\right.$-value), redness $\left(\mathrm{a}^{*}\right.$ value), and yellowness ( $b^{*}$-value) values were recorded.

\section{Cooking loss}

Cooking loss was determined by calculating the weight difference before and after cooking, as follows;

Cooking loss $(\%)=[($ raw sausage weight $(\mathrm{g})$

- cooked sausage weight $(\mathrm{g}) /$ /raw sausage weight $(\mathrm{g})] \times 100$

\section{Emulsion stability}

The chicken meat emulsion batters were analyzed for emulsion stability using the method of Blouka and Honikel (1992), with the following modifications. In the middle of a 15-mesh sieve, pre-weighed graduated glass tubes were filled with batter. The glass tubes were closed and heated for $30 \mathrm{~min}$ in a boiling water bath to a core temperature of $75 \pm 1^{\circ} \mathrm{C}$. After cooling to approximately $4 \pm$ $1^{\circ} \mathrm{C}$ to facilitate fat and water layer separation, the total expressible fluid and fat that separated in the bottom of graduated glass tube was measured (Choi et al., 2007b).

Total expressible fluid separation $(\%)=[($ water layer volume $(\mathrm{mL})+$ fat layer volume $(\mathrm{mL})) /$ raw meat batter weight $(\mathrm{g})] \times 100$

Fat separation $(\%)=[$ fat layer volume $(\mathrm{mL}) /$ raw meat batter weight $(\mathrm{g})] \times 100$

\section{Apparent viscosity}

The chicken emulsion meat batter viscosity was measured in triplicate with a rotational viscometer (HAKKE Viscotester ${ }^{\circledR} 500$, Thermo Electron Corporation, Karlsruhe, Germany) set at $10 \mathrm{rpm}$. The standard cylinder sensor (SV-2) was positioned in a $25 \mathrm{~mL}$ metal cup filled with batter and allowed to rotate under a constant share rate at $\mathrm{s}^{-1}$ for $60 \mathrm{~s}$ before each reading was taken. Apparent viscosity values in centipoises were obtained. The temperature of each sample at the time $\left(18 \pm 1^{\circ} \mathrm{C}\right)$ of viscosity testing was also recorded (Shand, 2000).

\section{Texture profile analysis (TPA)}

Texture measurements in the form of texture profile analysis were performed at room temperature with a texture analyzer (TA-XT2i, Stable Micro Systems, England). Chicken emulsion sausage samples were taken from the central portion of each frankfurter. Prior to analysis, samples were allowed to equilibrate to room temperature $\left(20^{\circ} \mathrm{C}, 3 \mathrm{~h}\right)$. The conditions of texture analysis were as follows: pre-test speed $2.0 \mathrm{~mm} / \mathrm{s}$, post-test speed $5.0 \mathrm{~mm} /$ $\mathrm{s}$, maximum load $2 \mathrm{~kg}$, head speed $2.0 \mathrm{~mm} / \mathrm{s}$, distance 8.0 $\mathrm{mm}$, force $5 \mathrm{~g}$. The calculation of TPA values was obtained by graphing a curve using force and time plots. Values for hardness $(\mathrm{kg})$, springiness, cohesiveness, gumminess $(\mathrm{kg})$, and chewiness $(\mathrm{kg})$ were determined as described (Bourne, 1978).

\section{Sensory evaluation}

Each chicken emulsion sausage was evaluated for color of appearance, flavor, tenderness, juiciness, and overall acceptability. Emulsion sausages were cooked with a center temperature of $75^{\circ} \mathrm{C}$, and the cooked samples were cooled to room temperature at $21^{\circ} \mathrm{C}$, cut into quarters, and served to panelists in random order. Each sample (size: $5 \times 5 \times 3 \mathrm{~cm}$ ) was coded with a randomly selected 3-digit numbers. Sensory evaluations were performed by the pan- 
elists under fluorescent lighting. Panelists were instructed to cleanse their palates between samples using water. The color $(1=$ extremely undesirable, $10=$ extremely desirable), flavor $(1=$ extremely undesirable, $10=$ extremely desirable), tenderness $(1=$ extremely tough, $10=$ extremely tender $)$, juiciness $(1=$ extremely dry, $10=$ extremely juicy $)$, and overall acceptability $(1=$ extremely undesirable, $10=$ extremely desirable) of the cooked samples were evaluated using a 10-point descriptive scale. The panel consisted of 11 members from the department of food sciences and biotechnology of animal resources at Konkuk University in Korea.

\section{Statistical analysis}

An analysis of variance was performed on all of the variables measured using the general linear model (GLM) procedure of the SAS statistical package (1999). Duncan's multiple range test $(p<0.05)$ was used to determine the differences between treatment means.

\section{Results and Discussion}

\section{Proximate composition and energy value}

The proximate composition and energy value of chicken emulsion sausages formulated with various chestnut peel levels $(0,1,2,3$, and $4 \%)$ are given in Table 2 . The differences in moisture, fat, ash, carbohydrate, and energy values of emulsion sausage were statistically significant $(p<0.05)$, but the protein content did not differ significantly among the control and treatment samples $(p>0.05)$. The moisture content was higher in treatments formulated with chestnut peel powder than the control, except for that of $4 \%$ chestnut peel powder treatment $(p<0.05)$. The fat content was the greatest in the control and $1 \%$ chestnut peel powder treatment; among the treatments with added powder, fat content was lower as added chestnut peel powder increased. The chicken emulsion sausage had an ash content ranging from $1.71 \%$ to $1.95 \%$; the ash content was higher in the treatments formulated with chestnut peel powder than in the control $(p<0.05)$. The ash content was also higher with increased added chestnut peel powder $(p<0.05)$. The carbohydrate content was lower in the treatment with added chestnut peel than the control samples, but did not significantly differ between the control and $3 \%$ and $4 \%$ chestnut peel powder treatments $(p>0.05)$. These results agree with those reported by Fernández-Ginés et al. (2004), who reported an application to bologna sausages with raw and cooked lemon albedo added. Choi et al. (2008) and Choi et al. (2009) reported similar results for meat products made with the addition of dietary fiber extracted from rice bran, and Hughes et al. (1997) indicated similar results for frankfurters formulated with oat fiber. Lee et al. (2009) showed that addition of kimchi fiber increased the moisture content of sausages. Kim et al. (2010) reported that the addition of sea tangle significantly raises the ash level. Eim et al. (2008) noted that fermented sausages containing carrot fiber were lower in fat and did not significantly differ in protein and ash content. The energy values of the chicken emulsion sausages ranged from 295.02 to 314.04 $\mathrm{kcal} / 100 \mathrm{~g}$. The lowest energy value was found in the $3 \%$ chestnut peel powder treatment. The energy value was affected by the sausages with fat contents. These results are in agreement with the results obtained by Choi et al. (2009) for meat products with added rice bran fiber and by Grigelmo-Miguel et al. (1999) for low-fat high dietary fiber frankfurters. Cengiz and Gokoglu (2005) reported that the energy values of sausage with added citrus fiber were significantly higher than those of control sausages. Similar results were obtained by Turhan et al. (2005) for low-fat meat products with hazelnut pellicle.

Table 2. Proximate composition of chicken emulsion sausage formulations with various chestnut peel powder levels

\begin{tabular}{ccccccc}
\hline \hline Treatments ${ }^{1)}$ & $\begin{array}{c}\text { Moisture } \\
(\%)\end{array}$ & $\begin{array}{c}\text { Protein } \\
(\%)\end{array}$ & $\begin{array}{c}\text { Fat } \\
(\%)\end{array}$ & $\begin{array}{c}\text { Ash } \\
(\%)\end{array}$ & $\begin{array}{c}\text { Carbohydrate } \\
(\%)\end{array}$ & $\begin{array}{c}\text { Energy value } \\
(\mathrm{kcal} / 100 \mathrm{~g})\end{array}$ \\
\hline Control & $55.40 \pm 0.75^{\mathrm{b}}$ & $11.26 \pm 0.51$ & $23.42 \pm 0.61^{\mathrm{a}}$ & $1.71 \pm 0.07^{\mathrm{c}}$ & $8.21 \pm 1.16^{\mathrm{a}}$ & $314.04 \pm 3.68^{\mathrm{a}}$ \\
T1 & $57.43 \pm 0.50^{\mathrm{a}}$ & $11.36 \pm 1.58$ & $22.99 \pm 0.27^{\mathrm{a}}$ & $1.78 \pm 0.08^{\mathrm{bc}}$ & $6.44 \pm 1.75^{\mathrm{b}}$ & $303.69 \pm 5.13^{\mathrm{bc}}$ \\
T2 & $57.46 \pm 0.54^{\mathrm{a}}$ & $12.61 \pm 1.34$ & $22.18 \pm 0.10^{\mathrm{b}}$ & $1.84 \pm 0.12^{\mathrm{b}}$ & $5.91 \pm 1.40^{\mathrm{b}}$ & $302.07 \pm 3.61^{\mathrm{c}}$ \\
T3 & $57.58 \pm 0.44^{\mathrm{a}}$ & $12.49 \pm 0.87$ & $20.95 \pm 0.93^{\mathrm{c}}$ & $1.88 \pm 0.10^{\mathrm{ab}}$ & $7.11 \pm 1.06^{\mathrm{a}}$ & $295.02 \pm 5.79^{\mathrm{d}}$ \\
T4 & $55.63 \pm 0.72^{\mathrm{b}}$ & $12.48 \pm 1.15$ & $22.03 \pm 0.32^{\mathrm{b}}$ & $1.95 \pm 0.04^{\mathrm{a}}$ & $7.91 \pm 1.56^{\mathrm{a}}$ & $307.92 \pm 3.16^{\mathrm{b}}$ \\
\hline
\end{tabular}

All values are mean \pm standard deviation of three replicates.

${ }^{\mathrm{a}-\mathrm{d}}$ Means within a column with different letters are significantly different $(p<0.05)$.

${ }^{1)}$ Control: chicken emulsion sausage with no addition; T1: chicken emulsion sausage with $1 \%$ chestnut peel powder; T2: chicken emulsion sausage with $2 \%$ chestnut peel powder; T3: chicken emulsion sausage with $3 \%$ chestnut peel powder; T4: chicken emulsion sausage with $4 \%$ chestnut peel powder. 


\section{pH and color}

Table 3 shows the $\mathrm{pH}$, lightness $\left(\mathrm{L}^{*}\right.$-value $)$, redness $\left(\mathrm{a}^{*}\right.$ value), and yellowness ( $b^{*}$-value) values of uncooked and cooked chicken emulsion sausages formulated with various chestnut peel powder levels. The $\mathrm{pH}$ of uncooked meat batter ranged from 6.18 to 6.25 , and the $\mathrm{pH}$ of cooked chicken meat sausage ranged from 6.28 to 6.45 . The $\mathrm{pH}$ of uncooked meat batter was lower in treatments with added chestnut peel powder than in the control, except in the $1 \%$ chestnut peel powder treatment sample. The $\mathrm{pH}$ of cooked sausage was the highest in the control without chestnut peel powder, as increasing chestnut peel powder levels of cooked chicken emulsion sausage lead to lower $\mathrm{pH}$ values due to the added chestnut peel powder. These results are similar to those reported by Jeong et al. (2006), who found significantly decreased $\mathrm{pH}$ with increasing levels of added chestnut peel powder levels for Takju. According to Choi et al. (2008), pH values of meat products were higher in the treatments with added rice bran levels due to the minerals in rice bran. Choi et al. (2007b) reported that the $\mathrm{pH}$ of meat batter did not differ significantly with added isolated soy protein, concentrated soy protein, and wheat fiber. The $\mathrm{pH}$ was higher in the cooked chicken emulsion sausages than uncooked meat batters, because meat product was increased when they were heated due to the basicity of the imidazolium moiety in the amino acid histidine, which is exposed upon denaturing (Choi et al., 2008, Forrest et al., 1975).

The differences in lightness, redness, and yellowness values of uncooked meat batters and cooked emulsion sausages were significant (Table 3 ). The lightness values of the uncooked meat batters and emulsion sausages decreased with increasing chestnut peel powder levels $(p<0.05)$. The redness and yellowness values of uncooked meat batters and cooked emulsion sausages increased sig- nificantly with increasing chestnut peel powder content $(p<0.05)$ due to the low lightness $(68.09 \pm 1.25)$ and high redness $(5.47 \pm 0.78)$ and yellowness $(11.31 \pm 0.81)$ of chestnut peel powder. Similar trends in color were observed in studies by Jeong et al. (2006) on addition of chestnut peel powder in foods. Lee et al. (2009) reported that the addition of kimchi powder in sausages resulted in higher redness and yellowness and lower lightness values than the control. These results agree with those reported by Calvo et al. (2008), who reported that the addition of tomato peel to fermented sausages lowers lightness values and increases redness and yellowness values compared to a control. Also, Choi et al. (2008) reported that the addition of rice bran in meat products led to changes in color. Thus, color changes have been reported as being induced by the presence of natural fiber of various origins in various meat products.

\section{Cooking loss and Emulsion stability}

The cooking loss and emulsion stability of chicken emulsion sausages formulated with various chestnut peel powder levels are shown in Table 4. Cooking loss was the highest in the control sample of emulsion sausages due to the high loss of fat and moisture during cooking. The cooking loss of samples with added chestnut peel powder was lower than that of the control, and the treatment containing $4 \%$ chestnut peel powder had the lowest cooking loss (T4) $(p<0.05)$. Similar results were obtained by Choi et al. (2008) for low-fat tteokgalbi with added rice bran and by Turhan et al. (2005) for low-fat beef burgers containing hazelnut pellicle. According to Choi et al. (2010), the cooking loss depend on the cooking time and temperature, condition of meat mixture, fat, and amounts of ingredients such as natural sources of dietary fiber and isolated soy protein in the meat products. In particular,

Table 3. Effects of $\mathbf{p H}$ and color $\left(\mathrm{L}^{*}-\mathrm{a}^{*}-\right.$, and $\mathbf{b}^{*}$-values) of chicken emulsion sausages formulated with various chestnut peel powder levels

\begin{tabular}{|c|c|c|c|c|c|c|c|c|}
\hline \multirow{2}{*}{ Treatments ${ }^{1)}$} & \multicolumn{4}{|c|}{ Meat batter } & \multicolumn{4}{|c|}{ Emulsion sausage } \\
\hline & $\mathrm{pH}$ & $\mathrm{L}^{*}$-value & $a^{*}$-value & $\mathrm{b}^{*}$-value & $\mathrm{pH}$ & $L^{*}$-value & $\mathrm{a}^{*}$-value & $\mathrm{b}^{*}$-value \\
\hline Control & $6.25 \pm 0.03^{\mathrm{a}}$ & $84.08 \pm 0.18^{\mathrm{a}}$ & $4.68 \pm 0.11^{\mathrm{e}}$ & $7.71 \pm 0.12^{\mathrm{d}}$ & $6.45 \pm 0.07^{\mathrm{a}}$ & $90.73 \pm 0.82^{\mathrm{a}}$ & $3.67 \pm 0.18^{\mathrm{e}}$ & $10.96 \pm 0.44^{b}$ \\
\hline $\mathrm{T} 1$ & $6.24 \pm 0.02^{\mathrm{a}}$ & $77.37 \pm 0.42^{\mathrm{b}}$ & $5.37 \pm 0.05^{\mathrm{d}}$ & $9.09 \pm 0.18^{c}$ & $6.40 \pm 0.06^{\mathrm{ab}}$ & $74.48 \pm 1.23^{\mathrm{b}}$ & $4.73 \pm 0.25^{\mathrm{d}}$ & $11.10 \pm 0.23^{b}$ \\
\hline $\mathrm{T} 2$ & $6.19 \pm 0.02^{b}$ & $72.56 \pm 0.22^{\mathrm{c}}$ & $5.72 \pm 0.15^{\mathrm{c}}$ & $9.97 \pm 0.25^{\mathrm{b}}$ & $6.32 \pm 0.10^{\mathrm{b}}$ & $66.81 \pm 1.66^{\mathrm{c}}$ & $6.44 \pm 0.34^{\mathrm{c}}$ & $11.55 \pm 0.30^{\mathrm{b}}$ \\
\hline $\mathrm{T} 3$ & $6.19 \pm 0.03^{b}$ & $68.41 \pm 0.31^{\mathrm{d}}$ & $6.48 \pm 0.14^{\mathrm{b}}$ & $10.39 \pm 0.30^{\mathrm{a}}$ & $6.31 \pm 0.08^{\mathrm{bc}}$ & $63.54 \pm 1.06^{\mathrm{d}}$ & $7.19 \pm 0.14^{\mathrm{b}}$ & $12.39 \pm 0.40^{\mathrm{a}}$ \\
\hline $\mathrm{T} 4$ & $6.18 \pm 0.03^{\mathrm{b}}$ & $66.30 \pm 0.31^{\mathrm{e}}$ & $7.05 \pm 0.10^{\mathrm{a}}$ & $10.59 \pm 0.22^{\mathrm{a}}$ & $6.28 \pm 0.08^{c}$ & $58.90 \pm 1.46^{\mathrm{e}}$ & $7.99 \pm 0.15^{\mathrm{a}}$ & $12.93 \pm 0.57^{\mathrm{a}}$ \\
\hline
\end{tabular}

All values are mean \pm standard deviation of three replicates.

${ }^{a-e}$ Means within a column with different letters are significantly different $(p<0.05)$.

${ }^{1)}$ Control: chicken emulsion sausage with no addition; T1: chicken emulsion sausage with $1 \%$ chestnut peel powder; T2: chicken emulsion sausage with $2 \%$ chestnut peel powder; T3: chicken emulsion sausage with $3 \%$ chestnut peel powder; T4: chicken emulsion sausage with $4 \%$ chestnut peel powder. 
Table 4. Effects of cooking loss and emulsion stability on chicken meat batters formulated with various chestnut peel powder levels

\begin{tabular}{cccc}
\hline \hline & \multirow{2}{*}{ Treatments $^{1)}$} & $\begin{array}{c}\text { Cooking loss } \\
(\%)\end{array}$ & \multicolumn{2}{c}{ Emulsion stability } \\
\cline { 3 - 4 } & & $\begin{array}{c}\text { Total expressible } \\
\text { fluid (\%) }\end{array}$ & $\begin{array}{c}\text { Fat loss } \\
(\%)\end{array}$ \\
\hline Control & $9.36 \pm 1.10^{\mathrm{a}}$ & $5.37 \pm 0.91^{\mathrm{a}}$ & $0.85 \pm 0.13^{\mathrm{a}}$ \\
T1 & $8.83 \pm 0.78^{\mathrm{ab}}$ & $5.02 \pm 0.14^{\mathrm{a}}$ & $0.72 \pm 0.04^{\mathrm{a}}$ \\
T2 & $8.33 \pm 0.43^{\mathrm{b}}$ & $4.62 \pm 0.43^{\mathrm{b}}$ & $0.69 \pm 0.04^{\mathrm{a}}$ \\
T3 & $7.43 \pm 0.25^{\mathrm{c}}$ & $4.04 \pm 0.95^{\mathrm{bc}}$ & $0.69 \pm 0.03^{\mathrm{a}}$ \\
T4 & $6.34 \pm 0.31^{\mathrm{d}}$ & $3.79 \pm 0.29^{\mathrm{c}}$ & $0.49 \pm 0.21^{\mathrm{b}}$ \\
\hline
\end{tabular}

All values are mean \pm standard deviation of three replicates.

${ }^{\mathrm{a}-\mathrm{d}}$ Means within a column with different letters are significantly different $(p<0.05)$.

${ }^{1)}$ Control: chicken emulsion sausage with no addition; T1: chicken emulsion sausage with $1 \%$ chestnut peel powder; T2: chicken emulsion sausage with $2 \%$ chestnut peel powder; T3: chicken emulsion sausage with $3 \%$ chestnut peel powder; T4: chicken emulsion sausage with $4 \%$ chestnut peel powder.

dietary fiber is likely to be the major contributor to water holding capacity, due to its high moisture absorption. Dietary fibers from different sources have been studied alone or in combination for formulation of various meat products, which can be used to decrease cooking loss by improving their water and fat binding properties.

Emulsion stability is known to be affected by the addition of different kinds of ingredient (Fernández-Ginés et al., 2004; Hughes et al., 1997; Turhan et al., 2005; Yang et al., 2007). Chicken emulsion sausages formulated with added chestnut peel powder had significant differences in emulsion stability (Table 4). The emulsion stability is an index that estimates the physical properties of a final meat product (Kim et al., 2010). According to Choi et al., (2007b), emulsion systems that have high emulsion stability do not extrude fat and water during cooking. The addition of chestnut peel powder to meat batters had significant effects on the emulsion stability of chicken emulsion systems. The water loss decreased with increasing chestnut peel powder levels, and the highest value was shown in the control and treatment with $1 \%$ chestnut peel powder. The fat loss of treatments with added $4 \%$ chestnut peel powder samples was the lowest $(p<0.05)$, but did not significantly differ among the control and other treatments samples with added chestnut peel powder $(p>0.05)$. Tan et al. (2006) reported that in stable meat batters containing different fats, no fluid loss was observed after $1 \mathrm{~h}$ at $75^{\circ} \mathrm{C}$, suggesting the formation of a strong emulsion complex. Similar results were reported by Choi et al. (2007a) for quality characteristics of meat model systems containing rice bran, and Kim et al. (2010) for breakfast sausages prepared with Lamina japonica powder. Choi et al. (2007b) reported that the addition of wheat fiber to meat emulsions improved emulsion stability and rheological properties.

\section{Apparent viscosity}

The various levels of chestnut peel powder significantly affected the viscosity of chicken meat emulsion systems (Fig. 1). In the control as well as all treatments with added chestnut peel powder, that apparent viscosity of meat batter was found to decrease with an increase in rotation time. The addition of chestnut peel powder to the formulation significantly affects the apparent viscosity of the products. The apparent viscosity of meat emulsions gradually increased as the chestnut peel powder levels treatments increased, and that in the chestnut peel powder treatments was significantly higher than that of the control. According to Aktas and Genccelep (2006), the high viscosity in the meat batters is not easily broken, and could yield a more consistent and viscoelastic end product. Shand (2000) showed that increased meat batter viscosity resulted in an increase in emulsion stability. Choi et al. (2007a) reported similar results for meat batters made with added rice bran. In general, meat emulsion systems had high correlations between emulsion viscosity and emulsion stability (Turgut et al., 1981; Zorba et al., 1993).

\section{Texture profile analysis}

The different chestnut peel powder levels affected the

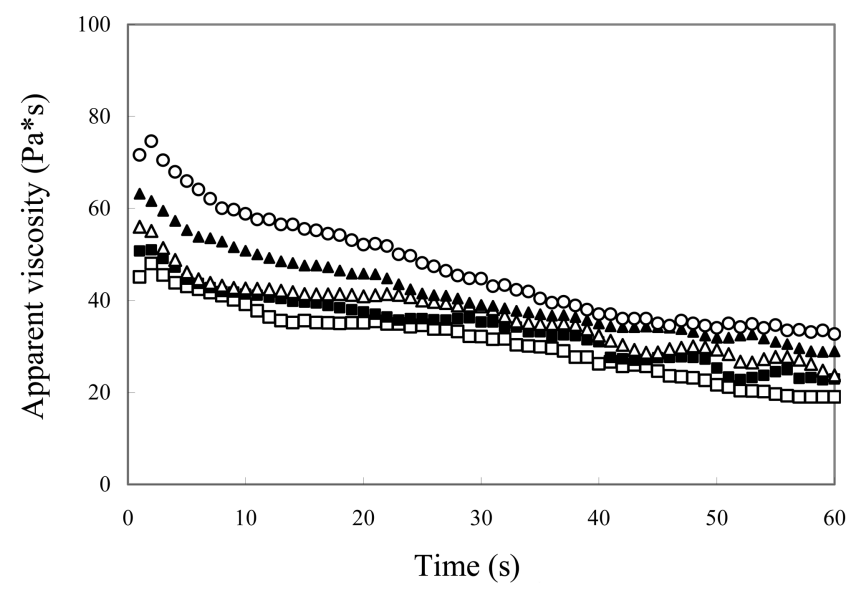

Fig. 1. Change in apparent viscosity of chicken meat batters containing chestnut peel powder stirred for 1 min. ( $\square$ ) Control, chicken meat batter with no addition; $(\mathbf{\square}) \mathrm{T} 1$, chicken meat batter with $1 \%$ chestnut peel powder; $(\triangle) \mathrm{T} 2$ chicken meat batter with $2 \%$ chestnut peel powder; $(\Delta) \mathrm{T} 3$ chicken meat batter with $3 \%$ chestnut peel powder; $(\bigcirc) \mathrm{T} 4$, chicken meat batter with $4 \%$ chestnut peel powder. 
textural properties of chicken emulsion sausages (Table 5). The emulsion sausages samples with $3 \%$ and $4 \%$ added chestnut peel powder had the highest hardness values, and as the chestnut peel powder levels increased, the hardness increased. Springiness was the highest for the $1 \%$ chestnut peel powder treatment sample. As chestnut peel powder increased among the treatments, springiness increased. The treatment with $2 \%$ chestnut peel powder was the highest cohesiveness, and that of $4 \%$ chestnut peel powder was the lowest $(p<0.05)$, and the gumminess of treatments with $4 \%$ added chestnut peel powder was higher than the control $(p<0.05)$. Chewiness did not significantly differ among the control and all treatments with added chestnut peel powder $(p>0.05)$. This agrees with Choi et al. (2010), who studied the effects of rice bran fiber on the textural properties of reduced-fat frankfurters. Calvo et al. (2008) reported that tomato peel increased the hardness of dry fermented sausages. Kim et al. (2010) obtained similar results of increasing hardness and decreasing springiness by the addition of sea tangle powder. According to Garcia et al. (2002), the hardness of meat products increased with added cereal fiber, while the addition of fruit fiber decreased the hardness of the same meat product. Xiong et al. (1999) reported that low-fat beef sausages with added xanthan gum had decreased hardness. In general, meat products such as emulsion sausage, patty, and nugget with added dietary fiber had improved textural properties (Cofrades et al., 2000; Kim et al., 2010; Lee et al., 2008; Steenblock et al., 2001). The significant increases in hardness that were recorded in the meat products containing dietary fiber were due to the fact that the samples with added dietary fiber had stronger binding ability than those without dietary fiber (Choi et al., 2009). Textural properties were also affected by water holding capacity, emulsion stability, gelling ability, and addition of other ingredients (Choi et al., 2008).

\section{Sensory evaluation}

The sensory values for cooked chicken emulsion sausages with different levels of chestnut peel powder are shown in Table 6. The mean values of color, flavor, tenderness, and juiciness were evaluated, as well as overall acceptability. The control without chestnut peel powder received the highest color scores, but both the control and all treatments with added chestnut peel powder did not differ significantly $(p>0.05)$. There were no significan in the flavor and tenderness scores among the control and all of the treatments containing chestnut peel powder ( $p>$ $0.05)$. The juiciness score of chicken emulsion sausages with added chestnut peel powder were significantly greater

Table 5. Effects of the textural attributes on chicken emulsion sausage formulated with varying chestnut peel powder levels

\begin{tabular}{cccccc}
\hline \hline Treatments $^{1)}$ & Hardness $(\mathrm{kg})$ & Springiness & Cohesiveness & Gumminess $(\mathrm{kg})$ & Chewiness $(\mathrm{kg})$ \\
\hline Control $^{\mathrm{l}}$ & $2.78 \pm 0.18^{\mathrm{b}}$ & $0.94 \pm 0.02^{\mathrm{ab}}$ & $0.54 \pm 0.02^{\mathrm{bc}}$ & $1.51 \pm 0.12^{\mathrm{b}}$ & $1.41 \pm 0.10$ \\
T1 & $2.91 \pm 0.24^{\mathrm{b}}$ & $0.98 \pm 0.09^{\mathrm{a}}$ & $0.57 \pm 0.05^{\mathrm{ab}}$ & $1.57 \pm 0.17^{\mathrm{b}}$ & $1.49 \pm 0.07$ \\
T2 & $2.92 \pm 0.18^{\mathrm{b}}$ & $0.95 \pm 0.03^{\mathrm{ab}}$ & $0.59 \pm 0.03^{\mathrm{a}}$ & $1.65 \pm 0.16^{\mathrm{ab}}$ & $1.48 \pm 0.11$ \\
T3 & $3.21 \pm 0.31^{\mathrm{a}}$ & $0.92 \pm 0.03^{\mathrm{bc}}$ & $0.55 \pm 0.02^{\mathrm{bc}}$ & $1.66 \pm 0.16^{\mathrm{ab}}$ & $1.50 \pm 0.15$ \\
T4 & $3.30 \pm 0.22^{\mathrm{a}}$ & $0.88 \pm 0.06^{\mathrm{c}}$ & $0.52 \pm 0.04^{\mathrm{c}}$ & $1.75 \pm 0.21^{\mathrm{a}}$ & $1.55 \pm 0.25$ \\
\hline
\end{tabular}

All values are mean \pm standard deviation of three replicates.

${ }^{a-c}$ Means within a column with different letters are significantly different $(p<0.05)$.

${ }^{1)}$ Control: chicken emulsion sausage with no addition; T1: chicken emulsion sausage with $1 \%$ chestnut peel powder; T2: chicken emulsion sausage with $2 \%$ chestnut peel powder; T3: chicken emulsion sausage with $3 \%$ chestnut peel powder; T4: chicken emulsion sausage with $4 \%$ chestnut peel powder.

Table 6. Effects of the sensory evaluation on chicken emulsion sausage formulated with varying chestnut peel powder levels

\begin{tabular}{cccccc}
\hline \hline Treatments $^{1)}$ & Color & Flavor & Tenderness & Juiciness & Overall acceptability \\
\hline Control & $8.13 \pm 0.83$ & $8.00 \pm 0.93$ & $7.88 \pm 0.35$ & $7.75 \pm 0.46^{\mathrm{c}}$ & $7.75 \pm 0.46^{\mathrm{ab}}$ \\
T1 & $8.00 \pm 0.93$ & $8.13 \pm 0.64$ & $7.75 \pm 0.46$ & $7.88 \pm 0.64^{\mathrm{bc}}$ & $8.15 \pm 0.71^{\mathrm{a}}$ \\
T2 & $7.88 \pm 0.99$ & $7.88 \pm 0.71$ & $8.00 \pm 0.53$ & $8.50 \pm 0.53^{\mathrm{ab}}$ & $8.25 \pm 0.46^{\mathrm{a}}$ \\
T3 & $7.75 \pm 0.71$ & $7.74 \pm 0.64$ & $8.25 \pm 0.71$ & $8.63 \pm 0.74^{\mathrm{a}}$ & $8.18 \pm 0.64^{\mathrm{a}}$ \\
T4 & $7.50 \pm 0.53$ & $7.50 \pm 0.53$ & $7.75 \pm 0.46$ & $8.13 \pm 0.64^{\mathrm{ab}}$ & $7.50 \pm 0.53^{\mathrm{b}}$ \\
\hline
\end{tabular}

All values are mean \pm standard deviation of three replicates.

${ }^{\mathrm{a}-\mathrm{c}}$ Means within a column with different letters are significantly different $(p<0.05)$.

${ }^{1)}$ Control: chicken emulsion sausage with no addition; T1: chicken emulsion sausage with $1 \%$ chestnut peel powder; T2: chicken emulsion sausage with $2 \%$ chestnut peel powder; T3: chicken emulsion sausage with $3 \%$ chestnut peel powder; T4: chicken emulsion sausage with $4 \%$ chestnut peel powder. 
than the control without chestnut peel powder, and was the greatest in the treatment with $3 \%$ chestnut peel powder sample $(p<0.05)$. Overall acceptability scores of chicken emulsion sausage were higher for $1 \%, 2 \%$, and $3 \%$ treatment with chestnut peel powder than for $4 \%$ treatment $(p<0.05)$. Chin and Gwang (2008) reported on product quality of low-fat sausages with added acorn powder as a fat replacer. Similar results were obtained by Yang et al. (2007) for low fat pork sausages with added oatmeal and tofu. These results agree with those reported by Choi et al. (2008), who noted significantly high scores in pork emulsion sausage with the addition of rice bran fiber. Fernández-Ginés et al. (2004) indicated that acceptability scores of bologna sausages was the higher obtained for sausages up to $5 \%$ raw albedo added, while in the case of cooked albedo, the samples with added $2.5 \%, 5 \%$, and $7.5 \%$ albedo added obtained the highest scores. However, Calvo et al. (2008) reported that the results of the hedonic test did not show significant differences among the control and treatment samples with added tomato peel powder, for all parameters such as odor, color, texture, taste, and overall acceptability of sensory properties.

\section{Conclusions}

Chestnut peel showed potential as a good source of dietary fiber that can be used as a functional ingredient for chicken emulsion sausages. Chicken emulsion sausages with added chestnut peel show improvement in their nutritional properties, and the chestnut peel may have other beneficial effects. Chicken emulsion sausages with added chestnut peel could be commercially acceptable meat products, and can be readily manufactured with high quality. The best results were obtained for chicken emulsion sausages with addition of $1 \%$ to up to $3 \%$ chestnut peel.

\section{Acknowledgements}

This work was supported by Ministry for Food, Agriculture, Forestry and Fisheries funded by the Korean Government (608001-05-2-SB310). The authors also partially supported by the Brain Korean 21 (BK 21) Project from Ministry of Education and Human Resources Development.

\section{Referencess}

1. Aktas, N. and Genccelep, H. (2006) Effect of starch type and its modifications on physicochemical properties of bolognatype sausage produced with sheep tail fat. Meat Sci. 74, 404408.

2. Aleson-Carbonell, L., Fernandez-Lopez, J., Sayas-Barbera, E., Sendra, E., and Perez-Alvarez, J. A. (2003) Utilization of lemon albedo in dry-cured sausages. J. Food Sci. 68, 1826-1830.

3. AOAC (2000) (17th ed.). Official methods of analysis of AOAC, Vol. 41. Washington DC: Association of Official Analytical Chemists.

4. Bloukas, I. and Honikel, K. O. (1992) The influence of additives on the oxidation of pork back fat and its effect on water and fat binding in finely comminuted batters. Meat Sci. 32, 31-43.

5. Calvo, M. M., Garcia, M. L., and Selgas, M. D. (2008) Dry fermented sausages enriched with lycopene from tomato peel. Meat Sci. 80, 167-172.

6. Cengiz, E. and Gokoglu, N. (2005) Changes in energy and cholesterol contents of frankfurter-type sausages with fat reduction and fat replacer addition. Food Chem. 91, 443-447.

7. Chin, K. B. and Ban, G. H. (2008) Evaluation of two levels and types of acorn powder on product quality of low-fat sausages as a fat replacer. J. Anim. Sci. Technol. (Kor.) 50, 217-226.

8. Choi, Y. S., Choi, J. H., Han, D. J., Kim, H. Y., Lee, M. A., Kim, H. W., Lee, C. H., Paik, H. D., and Kim, C. J. (2009) Physicochemical and sensory characterization of Korean blood sausage with added rice bran fiber. Korean J. Food Sci. Ani. Resour. 29, 260-268.

9. Choi, Y. S., Choi, J. H., Han, D. J., Kim, H. Y., Lee, M. A., Kim, H. W., Lee, J. W., Chung, H. J., and Kim, C. J. (2010) Optimization of replacing pork back fat with grape seed oil and rice bran fiber for reduced-fat meat emulsion systems. Meat Sci. 84, 212-218.

10. Choi, Y. S., Choi, J. H., Han, D. J., Kim, H. Y., Lee, M. A., Lee, E. S., Jeong, J. Y., Paik, H. D., and Kim, C. J. (2008) Effect of rice bran fiber on quality of low-fat tteokgalbi. Food Sci. Biotechnol. 17, 959-964.

11. Choi, Y. S., Jeong, J. Y., Choi, J. H., Han, D. J., Kim, H. Y., Lee, M. A., Shim, S. Y., Paik, H. D., and Kim, C. J. (2007a) Quality characteristics of meat batters containing dietary fiber extracted from rice bran. Korean J. Food Sci. Ani. Resour, 27, 228-234.

12. Choi, Y. S., Lee, M. A., Jeong, J. Y., Choi, J. H., Han, D. J., Kim, H. Y., Lee, E. S., and Kim, C. J. (2007b) Effects of wheat fiber on the quality of meat batter. Korean J. Food Sci. Ani. Resour, 27, 22-28.

13. Clavo, M. M., Garcia, M. L., and Selgas, M. D. (2008) Dry fermented sausages enriched with lycopene from tomato peel. Meat Sci. 80, 167-172.

14. Cofrades, S., Guerra, M. A., Carballo, J., Fernandes-Martin, F., and Colmenero, F. J. (2000) Plasma protein and soy fiber content effect on bologna sausage properties as influenced by fat level. J. Food Sci. 65, 281-287.

15. Eim, V. S., Simal, S., Rossello, C., and Femenia, A. (2008) Effects of addition of carrot dietary fibre on the ripening process of a dry fermented sausage (sobrassada). Meat Sci. 80, 173-182. 
16. Fernández-Ginés, J. M., Fernandez-López, J., Sayas-Barberá, E., Sendra, E., and Pérez-Álvarez, J. A. (2004) Lemon albedo as a new source of dietary fiber: application to bologna sausages. Meat Sci. 67, 7-13

17. Fernandez-Gins, J. M., Fernandez-Lopez, J., Sayas-Barbera, E., Sendra, E., and Perez-Alvarez, J. A. (2003) Effect of storage conditions on quality characteristics of bologna sausages made with citrus fiber. J. Food Sci. 68, 710-715.

18. Forrest, J. C., Aberle, E. D., Hedrick, H. B., Judge, M. D., and Merkel, R. A. (1975) Principles of meat processing. Principles of meat science. W. H. Freeman and Company. San Francisco, CA. pp. 190-226.

19. Garcia, M. L., Dominguez, R., Galvez, M. D., Casas, C., and Selgas, M. D. (2002) Utilization of cereal and fruit fibers in low fat dry fermented sausages. Meat Sci. 60, 227-236.

20. Grigelmo-Miguel, N., Abadias-Seros, M. I., and Martin-Belloso, O. (1999) Characterization of low-fat high dietary fibre frankfurters. Meat Sci. 52, 247-256.

21. Hughes, E., Cofrades, S., and Troy, D. J. (1997) Effects of fat level, oat fiber and carrageenan on frankfurters formulated with 5, 12 and 30\% fat. Meat Sci. 45, 273-281.

22. Inkaya, A. N., Gocmen, D., Ozturk, S., and Koksel, H. (2009) Investigation on the functional properties of chestnut flours and their potential utilization in low-fat cookies. Food Sci. Biotechnol. 18, 1404-1410.

23. Jeon, B. G. and Park, C. K. (2000) A study on the production of chestnut powder in the inner shell (endo carp) of a chestnut from its treatment plant - study on the utilities of separated powder from chestnut inner shell. J. of KOWREC $\mathbf{8}$, 111-120.

24. Jeong, J. W., Park, K. J., Kim, M. H., and Kim, D. S. (2006) Quality characteristics of takju fermentation by addition of chestnut peel powder. Korean J. Food Preserv. 13, 329-336.

25. Jiménez-Colmenero, F., Serrano, A., Ayo, J., Solas, M. T., Cofrades, S., and Carballo, J. (2003). Physicochemical and sensory characteristics of restructured beef steak with added walnuts. Meat Sci. 65, 1391-1397.

26. Joo, S. Y. and Chung, H. J. (2007) Effects of pectin and potato starch on the quality characteristics of low-fat pork patties. Korean J. Food Cookery Sci. 23, 824-831.

27. Kim, H. W., Choi, J H., Choi, Y. S., Han, D. J., Kim, H. Y., Lee, M. A., Kim, S. Y., and Kim, C. J. (2010) Effects of sea tangle (Lamina japonica) powder on quality characteristics of breakfast sausages. Korean J. Food Sci. Ani. Resour. 30, 55-61.

28. Kim, S. H., Lee, K. S., Suh, D. S., Lee, Y. C., and Kim, K. O. (2008) Properties of chestnut starches and steamed chestnuts with different pretreatment and storage conditions. Food Sci. Biotechnol. 17, 534-539.

29. Lee, M. A., Han, D. J., Choi, J. H., Choi, Y. S., Kim, H. Y., Ahn, K. I., Jeong, J. Y., Lee, C. H., and Kim, C. J. (2009) Physico-chemical and sensory characteristics of semi-dried sausages containing different levels of kimchi powder. Korean J. Food Sci. Ani. Resour. 29, 557-565.

30. Lee, M. A., Han, D. J., Choi, J. H., Choi, Y. S., Kim, H. Y.,
Choe, J. H., Jeong, J. Y., and Kim, C. J. (2008) Effect of hot air dried kimchi powder on the quality characteristics of pork patties. Korean J. Food Cookery Sci. 24, 466-472.

31. Nuria, G. M., Maria-Isabel, A. S., and Olga, M. B. (1999) Characteristics of low-fat high-dietary fiber frankfurters. Meat Sci. 52, 257-256.

32. Oh, S. H., Kim, Y. W., and Kim, M. A. (2004) The antioxidant activities of acetone extracts of chestnut inner shell, pine needle and hop. Korean J. Food Culture 19, 399-406.

33. Oh, S. H., Kim, Y. W., and Kim, M. A. (2005) The antioxidant activities of three solvent (ether, butanol, water) extrats from chestnut inner shell in soybean oil. Korean J. Food Culture 20, 703-708.

34. SAS (1999) SAS/STAT Software. Release 8.1, SAS Institute Inc., Cary, NC, USA.

35. Shand, P. J. (2000) Textural, water holding, and sensory properties of low-fat pork bologna with normail and waxy starch hull-less barley. J. Food Sci. 65, 101-107.

36. Steenblock, R. L., Seeranek, J. G., Olson, D. G., and Love, J. A. (2001) The effects of oat fiber on the properties of light bologna and fat-free frankfurters. J. Food Sci. 66, 14091415.

37. Tan, S. S., Aminah, A., Zhang, X. G., and Abdul, S. B. (2006) Optimizing palm oil and palm sterarin utilization for sensory and textural properties of chicken frankfurters. Meat Sci. 72, 387-397.

38. Turgut, H., Varol, M., Uygun, M., and Er, R. (1981) Studies on determining of the emulsion capacity of beef, buffalo, lamb and goat meats between different oil and fats, Gebze, Turkey: TUBITAK Marmara Scientific and Industrial Research Ins. Press.

39. Turhan, S., Sagir, I., and Ustun, N. S. (2005) Utilization of hazelnut pellicle in low-fat beef burgers. Meat Sci. 71, 312316.

40. Wang, H. X. and Ng, T. B. (2003) Purification of castamollin, a novel antifungal protein from Chinese chestnuts. Protein Expre. Purif. 32, 44-52.

41. Xiong, Y. L., Noel, D. C., and Moody, W. G. (1999) Textural and sensory properties of low-fat beef sausages with added water and polysaccharides as affected by $\mathrm{pH}$ and salt. $J$. Food Sci. 64, 550-554.

42. Yang, B., Jiang, G., Gu, C., Yang, H., and Jiang, Y. (2010) Structural changes in polysaccharides isolated from chestnut (Castanea mollissima B1.) fruit at different degrees of hardening. Food Chem. 119, 1211-1215.

43. Yang, H. S., Choi, S. G., Jeon, J. T., Park, G. B., and Joo, S. T. (2007) Textural and sensory properties of low fat pork sausages with added hydrated oatmeal and tofu as texture-modifying agents. Meat Sci. 75, 283-289.

44. Zorba, O., Gokalp, H. Y., Yetim, H., and Ockerman, H. W. (1993) Salt, phophate and oil temperature effects on emulsion capacity of fresh or frozen meat and sheep tail fat. $J$. Food Sci. 58, 492-496.

(Received 2010.8.20/Accepted 2010.10.1) 